\title{
Clinical Experiences of Molecular Genetic Evaluation of Achondroplasia in Prenatal and Neonatal Cases
}

\author{
Dong Wook Kwak', Hyun Jin Kim², So Yeon Park², Hyun Suk Ahn', Yong Hwa Chae', Moon Young Kim', Young Ho Lee ${ }^{3}$ and Hyun \\ Mee Ryu ${ }^{1,2 *}$ \\ 'Department of Obstetrics and Gynecology, Cheil General Hospital and Women's Healthcare Center, Kwandong University, College of Medicine, \\ Seoul, Korea \\ 'Laboratory of Medical Genetics, Cheil General Hospital and Women's Healthcare Center, Seoul, Korea \\ ${ }^{3}$ Department of Radiology, Cheil General Hospital and Women's Healthcare Center, Kwandong University, College of Medicine, Seoul, Korea
}

Purpose: The purpose of this study was to assess the characteristics of achondroplasia (ACH) diagnosed in fetuses or neonates and to evaluate the usefulness of a molecular genetic testing to confirm ACH.

Materials and Methods: The medical and ultrasonographic records of 16 pregnant women, who had molecular genetic testing for $\mathrm{ACH}$ performed on their fetus or neonate at the Cheil General Hospital between February 1999 and April 2013, were retrospectively analyzed. Detection of G1138A and G1138C mutations of the fibroblast growth factor receptor 3 (FGFR3) gene was accomplished by polymerase chain reaction - restriction fragment length polymorphism analysis.

Results: Of the eight fetuses and two neonates who were suspected of having $\mathrm{ACH}$ during pregnancy, four fetuses and one neonate was confirmed to have $\mathrm{ACH}$ and they all carried the heterozygous G1138A mutation. Out of 6 cases which had a history of ACH in prior pregnancies, three had genetic information for the previous fetuses while the other three did not. All six fetuses had no mutations at G380R. However, the one fetus of pregnant woman with non-confirmed ACH showed shortened long bone on ultrasound thereafter and the fetus was identified as having oto-spondylo-megaepiphyseal dysplasia after birth.

Conclusion: Korean patients with achondroplasia have the heterozygous G1138A mutation that is most commonly defined in other countries. Molecular genetic evaluations of $\mathrm{ACH}$ are helpful not only for establishing diagnosis but for appropriate counseling with subsequent pregnancies.

Keywords: Achondroplasia, Prenatal diagnosis, Ultrasonography, Fibroblast growth factor receptor 3 gene

\section{Introduction}

Achondroplasia $(\mathrm{ACH}, \mathrm{OMIM} 100800)$ is the most common form of short limbed dwarfism, occurring at a frequency about 1 in $15000 .{ }^{1,2)} \mathrm{ACH}$ is characterized by short stature with disproportionately short arms and legs, a large head, characteristic facial features of frontal bossing and mid-face hypoplasia, exaggerated lumbar lordosis, genu varum and trident hands. ${ }^{3)}$ $\mathrm{ACH}$ is inherited as an autosomal dominant trait with 100\% penetrance. More than $90 \%$ of affected individuals have de novo mutations associated with increased paternal age. ${ }^{4,5)}$ The gene responsible for achondroplasia, fibroblast growth factor receptor

Received: 28 May 2013, Revised: 13 June 2013, Accepted: 21 June 2013, Published: 30 June 2013

*Corresponding author: Hyun Mee Ryu, M.D., Ph.D.

Department of Obstetrics and Gynecology, Cheil General Hospital and Women's Healthcare Center, Kwandong University College of Medicine, 1-19 Mukjeong-dong, Jung-gu, Seoul 100-380, Korea

Tel: +82-2-2000-7682, Fax: +82-2-2278-4574, E-mail: hmryu@yahoo.com

Conflict of interest: We declare that we do not have any conflicts of interests.

(c) This is an open-access article distributed under the terms of the Creative Commons Attribution Non-Commercial License (http://creativecommons.org/licenses/by-nc/3.0/) which permits unrestricted non-commercial use, distribution, and reproduction in any medium, provided the original work is properly cited.

(c) Copyright 2013 by the Korean Society of Medical Genetics 
3 (FGFR3), has been mapped to the short arm of chromosome 4 (4p16.3), and a predominant mutation, a $\mathrm{G}$ to $\mathrm{A}$ transition at nucleotide 1138 , has been found in more than $95 \%$ of the affected individuals. ${ }^{6,7)}$ A second mutation described in about $2 \%$ of achondroplasia patients is a $\mathrm{G}$ to $\mathrm{C}$ transition at the same position. Both mutations result in the substitution of an arginine for a glycine residue at position 380 of the FGFR3 protein. ${ }^{6-8)}$

Since prenatal ultrasound has become common in routine obstetric care and often includes measurement of the long bones, unanticipated findings of shortened long bone are detected sometimes. This finding will often be secondary to $\mathrm{ACH}$, but the diagnosis of ACH by ultrasound is known to be difficult. For this reason, molecular analysis has been used for a definite diagnosis in utero during the last few years.

The aim of this study was to assess the characteristics of achondroplasia which is diagnosed in pregnant Korean women and to evaluate the usefulness of molecular genetic studies to confirm the diagnosis of ACH.

\section{Material and Methods}

We retrospectively reviewed the medical records of fourteen pregnant women and two neonates who had molecular genetic studies performed for the verification of ACH at the Cheil General Hospital between February 1999 and April 2013. The study was approved by the Ethics Committee of the Institutional Review Board at Cheil General Hospital.

Genomic DNA was extracted from cultured amniotic fluid, umbilical cord blood and peripheral blood using a OlAamp DNA Mini kit (Qiagen, Hilden, Germany) according to the manufacturer's recommendations. PCR was amplified using the primers of Shiang et al., F: 5'-AGGAGCTGGTGGAGGCTGA-3', R: 5'-GGAGATCTTGTGCACGGTGG-3'. PCR-restriction fragment length polymorphism analysis analysis using the Mspl and $\mathrm{SfCl}$ restriction enzymes was performed for detection of G-to-A and G-to-C substitution at the position of the FGFR3 cDNA sequence that causes $\mathrm{ACH}^{7}{ }^{7}$

\section{Results}

In a total of 16 cases, ten patients including eight fetuses and two neonates underwent genetic studies due to suspicion of $\mathrm{ACH}$ and six pregnant women were tested due to suspicion of or confirmed ACH history in a prior pregnancy. Characteristics of the study population and the number of patients according to indication of the genetic studies are shown in Table 1.

\section{Pregnant women who underwent genetic evaluation due to suspicion of achondroplasia on prenatal ultrasound $(\mathrm{n}=8)$}

Two cases who suspected of ACH on ultrasounds at about 20 weeks' gestation found no mutation on G380R. Four out of 6 cases between 27 and 32 weeks' gestation were confirmed to have mutation on $\mathrm{G} 380 \mathrm{R}$ with the $\mathrm{G}$ to $\mathrm{A}$ transition at nucleotide 1138. One out of the four cases without a mutation at G380R showed a normal infantogram after birth. However, case 5 showed a low nasal bridge and proptosis as well as shortened long bone after birth and was ultimately referred to a tertiary pediatric center (Table 2).

\section{Neonates who underwent genetic evaluation due to suspicion of achondroplasia after birth $(n=2)$}

Case 9 was confirmed to have the $G$ to $A$ transition at nucleotide 1138. Case 10 with short neck, scoliosis, and cryptochidism as well as shortened long bones had no mutation at G380R. The mother of case 10 had an obstetric history of an antecedent fetus with hand deformity, scoliosis, and anorectal agenesis with rectovaginal fistula (Table 3).

\section{Pregnant women who had genetic evaluation performed due to suspected or confirmed history of achondroplasia in prior pregnancies $(n=6)$}

Among 6 cases with a history of $\mathrm{ACH}$ in prior pregnancies, three had molecular genetic information for the previous fetuses while the other three did not. All six cases showed no mutations

Table 1. Clinical Characteristics of the Study Population

\begin{tabular}{lc}
\hline Characteristic & Mean \pm SD or N (\%) \\
\hline Characteristics of study population & \\
Maternal age (years) & $33.2 \pm 2.4$ \\
Paternal age (years) & $35.0 \pm 2.8$ \\
Diagnosis of ACH on ultrasound (week) & $27.5 \pm 4.9$ \\
Indication for genetic evaluation & \\
Suspected ACH on ultrasound & $8(50 \%)$ \\
Suspected ACH on appearance after birth & $2(12 \%)$ \\
Prior history of confirmed ACH & $3(19 \%)$ \\
Prior history of suspected ACH & $3(19 \%)$ \\
\hline
\end{tabular}

$\mathrm{ACH}$, achondroplasia; SD, standard deviation 
Table 2. Patients Suspected of Having Fetuses with Achondroplasia on Prenatal Ultrasound

\begin{tabular}{lcccccccc}
\hline Case no. & Maternal age & Paternal age & Diagnosis (wk) & Test (wk) & $\begin{array}{c}\text { Material for } \\
\text { genetic study }\end{array}$ & Karyotype & G380R mutation & $\begin{array}{c}\text { Remark (outcome of this } \\
\text { pregnancy) }\end{array}$ \\
\hline 1 & 32 & 33 & 30 & 30 & CB & Normal & Positive (G1138A) & - \\
2 & 31 & 32 & 30 & 30 & CB & Normal & Positive (G1138A) & - \\
3 & 34 & 35 & 27 & 27 & CB & Normal & Positive (G1138A) & - \\
4 & 37 & 38 & 30 & 30 & AF & N/M & Positive(G1138A) & - \\
5 & 31 & 30 & 27 & 27 & AF & Normal & Negative & $\begin{array}{c}\text { Low nasal bridge, } \\
\text { proptosis }\end{array}$ \\
6 & 34 & 36 & 32 & 32 & CB & Normal & Negative & Normal by infantogram \\
7 & 36 & 37 & 20 & 20 & AF & Normal & Negative & Follow up loss \\
8 & 35 & 34 & 20 & 20 & AF & Normal & Negative & Ongoing pregnancy \\
\hline
\end{tabular}

AF, amniotic fluid; $\mathrm{CB}$, cord blood; N/M, not measured

Table 3. Neonates Suspected of Having Fetuses with Achondroplasia on Appearance after Birth

\begin{tabular}{lccccccc}
\hline Case no. & Maternal age & Paternal age & Previous pregnancy & G380R mutation & Karyotype & $\begin{array}{c}\text { Diagnosis week of short long } \\
\text { bone on antenatal ultrasound }\end{array}$ & $\begin{array}{c}\text { Remark (Outcome of } \\
\text { this pregnancy) }\end{array}$ \\
\hline 9 & 36 & 36 & Normal & Positive (G1138A) & Normal & 35 & - \\
10 & 34 & 37 & Multiple anomaly* & Negative & Normal & 24 & $\begin{array}{c}\text { Short neck, Scoliosis } \\
\text { Cryptochidism }\end{array}$ \\
\hline
\end{tabular}

*hand deformity, scoliosis, and anorectal agenesis with rectovaginal fistula

Table 4. Patients with Antecedent Pregnancy History of Achondroplasia

\begin{tabular}{lcccccccc}
\hline Case no. & Maternal age & Paternal age & $\begin{array}{c}\text { Material for } \\
\text { genetic study }\end{array}$ & $\begin{array}{c}\text { Previous } \\
\text { ACH }\end{array}$ & $\begin{array}{c}\text { G380R } \\
\text { mutation }\end{array}$ & Karyotype & Sonography & Remark (Outcome of this pregnancy) \\
\hline 11 & 31 & 34 & AF & Confirmed & Negative & Normal & Normal & - \\
12 & 35 & 41 & AF & Confirmed & Negative & Normal & Normal & - \\
13 & 34 & 35 & AF & Confirmed & Negative & Normal & N/M & Follow up loss \\
14 & 30 & 37 & AF & Suspected & Negative & Normal & Normal & Preterm delivery, VSD, PDA \\
15 & 30 & 32 & AF & Suspected & Negative & Normal & Normal & Bilateral club foot \\
16 & 36 & 37 & AF & Suspected & Negative & Normal & Abnormal & Oto-spondylo-megaepiphyseal dysplasia \\
\hline
\end{tabular}

$\mathrm{ACH}$, achondroplasia; $\mathrm{AF}$, amniotic fluid; VSD, ventricular septal defect; PDA, patent ductus arteriosus; N/M, not measured

at G380R and normal karyotype by amniocentesis between 16 and 18 weeks of gestation. Case 16 was recognized as having shortened long bones on mid-trimester ultrasound and showed micrognathia, bilateral club foot and flexion deformity in bilateral hip, knee and elbow joint as well as mildly disorganized epiphyseal growth zone. These findings are consistent with oto-spondylomegaepiphyseal dysplasia (OSMED). Another fetus showed bilateral club foot but he did not have any other abnormal findings (Table 4).

\section{Discussion}

We examined 16 patients who had molecular genetic testing performed for the diagnosis of $\mathrm{ACH}$. Among these cases, eight pregnant women were suspected to have $\mathrm{ACH}$ by abnormal ultrasound findings and underwent this study prenatally. Ultrasound is the primary imaging modality used for the diagnostic evaluation of a fetus with skeletal dysplasia. Lethal forms of skeletal dysplasia are frequently distinguishable by ultrasound even from the 18th week of gestation by femurs angulated like a telephone receiver, but heterozygous achondroplasia is typically only suspected during third trimester ultrasounds after detection of shortened long bones. Gaffney et al. reported four cases detected at 31-37 weeks, ${ }^{9)}$ while Doray et al. reported seven fetuses detected at 28-35 weeks. ${ }^{10)}$ However, there is a recent report in which rhizomelic shortening of the long bones less than 2 standard deviations was diagnosed at 17 weeks of gestation in a fetus with $\mathrm{ACH}^{1{ }^{11)}}$ According to the report by Modaff et al., misdiagnoses of heterozygous $\mathrm{ACH}$ can result in inappropriate pre- and perinatal decision-making regarding both interventions for fetal indications and termination of pregnancy. Therefore 
they recommended that FGFR3 mutation analysis (as well as cytogenetic assessment) should be offered in instances where a short limb disorder is detected ultrasonographically. ${ }^{12)}$ In the current study, two cases involved suspected $\mathrm{ACH}$ at around 20 week' gestation but they were found to have no mutation at G380R. The rest of the six cases were recognized from 27 to 32 weeks and four of them (66\%) were then confirmed by genetic testing to have $\mathrm{ACH}$. Furthermore, all fetuses showed normal karyotype except one that underwent only molecular genetic testing. Hatzaki et al. reported that all nine $\mathrm{ACH}$ fetuses in their study were recognized after 27 weeks and the fetuses with confirmed ACH had normal biometric parameters at around 20 weeks' gestation. ${ }^{13)}$ These findings support our data. Therefore, if shortened long bone is recognized on ultrasound at around 20 weeks' gestation, one must consider other forms of skeletal dysplasia. In addition, we have presented two neonate cases that had suspected of having $\mathrm{ACH}$ on appearance after birth and one of them was confirmed to have $\mathrm{ACH}$ by genetic testing, while the other was not. In these cases, the fetuses had already shown shortened long bone on the prenatal ultrasound, but genetic evaluations had not been carried during the pregnancies. In summary, five of ten fetuses suspected of having $\mathrm{ACH}$ were genetically confirmed to have $\mathrm{ACH}$ and the other five fetuses were not. Among the latter five, one fetus showed a normal infantogram. However, two of the non-ACH fetuses were suspected of having other forms of skeletal dysplasia and they were referred to a tertiary center (case 5 and 10 ).

It used to be assumed that the recurrence risk for siblings of children with an autosomal dominant condition of high penetrance, whose parents were normal, was close to twice the mutation rate. ${ }^{14)}$ However, the occurrence of $\mathrm{ACH}$ in siblings of achondroplastic children with normal parents appears to be rare. According to the data from 11 Canadian genetic centers, recurrence risk was estimated to be $1 / 443 .^{14)}$ Our data also showed that all three pregnant women, who had a history of a previous $\mathrm{ACH}$ fetus, had no mutation in this pregnancy. For these three cases, we were able to identify the results of previous molecular genetic studies and they also showed the $\mathrm{G}$ to $\mathrm{A}$ transition at nucleotide 1138. In the literature, more than $95 \%$ of patients with $\mathrm{ACH}$ from differentethnic groups carry the $G 380 R$ mutation resulting a $G$ to $A$ transition at position 1138 in the FGFR3 gene. ${ }^{6,7)}$ We identified the molecular genetic results of $8 \mathrm{ACH}$ patients, including 5 fetuses and 3 siblings, and all carried the $G$ to $A$ transition at position 1138 . According to our data and a review of the Korean literature, the homogeneity of the point mutation at 1138 is also authentic in the Korean population. ${ }^{15)}$ There were another three patients with suspected ACH in previous pregnancies, but they terminated their pregnancies without genetic evaluations and they didn't carry out autopsies, so ACH could not be confirmed in these cases. For these three, their molecular genetic studies of ACH and karyotype also showed no abnormal findings in this pregnancy. However one of fetuses showed shortened long bone in the mid-trimester ultrasound and the fetus had additional characteristics of OSMED. OSMED is an autosomal recessive dwarfism disorder characterized by limb shortening, multiple skeletal and radiological abnormalities, mid-face hypoplasia with a flat nasal bridge, small upturned nasal tip, and sensorineural hearing loss. ${ }^{14)}$

Since the features of skeletal dysplasia on ultrasound are similar, accurate diagnosis of $\mathrm{ACH}$ is difficult without genetic evaluation. However, according to our data, diagnosis of achondroplasia on ultrasound during the third trimester is somewhat accurate. Therefore, if it is not overused, the molecular genetic test of $\mathrm{ACH}$ might be reasonable. Also, pregnant women, whose fetuses are confirmed to have $\mathrm{ACH}$ through genetic testing, must be offered counseling for subsequent pregnancies, such as recurrence risk. Furthermore, we must keep in mind that some kinds of skeletal dysplasias other than $\mathrm{ACH}$ occasionally recur.

In conclusion, Korean patients with $\mathrm{ACH}$ have the same mutation that has been most often defined in other countries. When definite shortened long bone is recognized in the third trimester, ACH might be the most likely cause in Korean pregnant women. However, if patients have a history of conceiving a fetus with a skeletal dysplasia other than $\mathrm{ACH}$ or if the findings of shortened long bones were shown at a mid-trimester ultrasound, we must consider the possibility of other forms of skeletal dysplasia.

\section{References}

1. Murdoch JL, Walker BA, Hall JG, Abbey H, Smith KK, McKusick VA Achondroplasia: a genetic and statistical survey. Ann Hum Genet 1970;33:227-44.

2. Gardner RJ. A new estimate of the achondroplasia mutation rate. Clin Genet 1977;11:31-8.

3. Horton WA, Hall JG, Hecht JT. Achondroplasia. Lancet 2007;370:16272.

4. Vajo Z, Francomano CA, Wilkin DJ. The molecular and genetic basis of fibroblast growth factor receptor 3 disorders: the achondroplasia family of skeletal dysplasia, Muenke craniosynostosis and Crouzon syndrome with acanthosis nigricans. Endocr Rev 2000;21:23-39.

5. Rolf C, Nieschlag E. Reproductive functions, fertility and genetic risks 
of ageing men. Exp Clin Endocrinol Diabetes 2001;109:68-74.

6. Rousseau F. Bonaventure J, Legeall-Mallet L, Pelet A, Rozet JM, Maroteaux $\mathrm{P}$, et al Mutations in the gene encoding fibroblast growth factor receptor-3 in achondroplasia. Nature 1994;371:252-4.

7. Shiang $R$, Thompson LM, Zhu YZ, Church DM, Fielder TJ, Bocian M, et al. Mutations in the transmembrane domain of FGFR3 cause the most common genetic form of dwarfism, achondroplasia. Cell 1994;78:33542.

8. Bellus GA, McIntosh I, Smith EA, Aylsworth AS, Kaitila I, Horton WA, et al. Arecurrent mutation in the tyrosine kinase domain of fibroblast growth factor receptor 3 causes hypochondroplasia. Nat Genet 1995;10:357-9.

9. Gaffney G, Manning N, Boyd PA, Rai V, Gould S, Chamberlain P. Prenatal sonographic diagnosis of skeletal dysplasias - a report of the diagnostic and prognostic accuracy in 35 cases. Prenat Diagn 1998;18:357-62.

10. Doray B, Favre R, Viville B, Langer B, Dreyfus $M$, Stoll C. Prenatal sonographic diagnosis of skeletal dysplasias. A report of 47 cases. Ann
Genet 2000:43:163-9.

11. Tonni G, Ventura A, De Felice C. First trimester increased nuchal translucency associated with fetal achondroplasia. Am J Perinatol 2005;22:145-8.

12. Modaff P, Horton VK, Pauli RM. Errors in the prenatal diagnosis of children with achondroplasia. Prenatal Diagnosis 1996;16:525-30.

13. Hatzaki A, Sifakis S, Apostolopoulou D, Bouzarelou D, Konstantinidou A, Kappou D, et al. FGFR3 related skeletal dysplasias diagnosed prenatally by ultrasonography and molecular analysis: presentation of 17 cases. Am J Med Genet A 2011;155A:2426-35.

14. Melkoniemi M, Brunner HG, Manouvrier S, Hennekam R, Superti-Furga

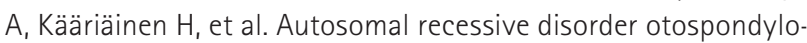
megaepiphyseal dysplasia is associated with loss-of-function mutations in the COL11A2 gene. Am J Hum Genet 2000;66:368-77.

15. Shin S, Choi IH, Cho TJ, Ryang SW, Yoon KY, Kim J, et al. Mutation analysis of Fibroblast Growth Factor Receptor 3 (FGFR3) Gene in Korean Patients with Achondroplasia and Hypochondroplasia. Korean J Clin Pathol 2001;21:164-8. 